\title{
Empowering Patients and Supporting Health Care Providers-New Avenues for High Quality Care and Safety
}

\author{
Isolde Martina Busch (1) and Michela Rimondini * \\ Department of Neurosciences, Biomedicine and Movement Sciences, University of Verona, 37134 Verona, Italy; \\ isoldemartina.busch@univr.it \\ * Correspondence: michela.rimondini@univr.it
}

Citation: Busch, I.M.; Rimondini, M. Empowering Patients and Supporting Health Care Providers-New Avenues for High Quality Care and Safety. Int. J. Environ. Res. Public Health 2021, 18, 9438.

https://doi.org/ 10.3390/ijerph18189438

Received: 26 August 2021

Accepted: 1 September 2021

Published: 7 September 2021

Publisher's Note: MDPI stays neutral with regard to jurisdictional claims in published maps and institutional affiliations.

Copyright: (c) 2021 by the authors. Licensee MDPI, Basel, Switzerland. This article is an open access article distributed under the terms and conditions of the Creative Commons Attribution (CC BY) license (https:// creativecommons.org/licenses/by/ $4.0 /)$.
A large body of research suggests that establishing and strengthening patient-provider relationships, characterized by transparency, respect, trust, and empathy, is highly beneficial for patients, their caregivers, and healthcare providers [1-5]. However, due to disintegrated care and work pathways, staff reduction, and time pressures, the human aspects in the medical setting are often overlooked or disregarded [5-7]. Indeed, patients whose individual needs are underestimated may feel disrespected, disempowered, and dissatisfied with their care [5,8-11]. Moreover, healthcare providers are primarily assessed by their professional performance and are often under excessive work pressures, which can result in emotional distress and burnout $[5,7,12,13]$.

The current COVID-19 pandemic has negatively influenced the psychological wellbeing of the general public, of patients, and healthcare providers in particular [14-19], worsening the above-described trend and emphasizing the urgent need for an integrative approach to healthcare that empowers patients, supports the healthcare workforce, and enhances public health efforts.

Following this rationale, this Special Issue covers high-quality, timely research on person-centered care, patient-physician communication, health literacy, healthcare providers' professional and emotional well-being, and patient safety culture. Its overall structure takes the form of nine papers, comprising qualitative and quantitative studies, systematic reviews, and a theoretical paper, which make for compelling reading.

With regard to advancing patient care, the feasibility study by Lewandowski et al. [19] describes the process of implementing person-centered care for pediatric patients with moderate scoliosis in a Polish rehabilitation hospital. Using semi-structured interviews and applying content analysis, the results showed that patients and their families, as well as healthcare providers, perceived the approach as beneficial and feasible. The authors suggest that this type of care might even lead in the long run to reduced healthcare expenses and better quality of life for patients. Similarly, Madani Larijani et al. [20] promoted patient engagement by involving patients in the development of a tool tackling the overuse of lower back pain imaging. According to Madani Larijani et al. [20], the patient-oriented prescription pad, which gives information on the technique's risks and benefits, may help empower patients by equipping them with knowledge and increasing patient involvement in medical decision making and fostering the patient-physician relationship. Van der Velden et al. [21] focused on a particularly difficult issue that may arise in patient-physician relations, namely, discussing prognoses for patients with advanced cancer who seek another oncologist for a second opinion. The qualitative study, investigating the conversations between patients with advanced cancer and their consulting oncologists, showed that oncologists were cautious in providing prognosis despite patients' implicitly communicated cues and explicitly posed questions. A useful approach for tackling challenging topics in healthcare conversations, such as cancer prognosis, is described in the study by Borghi et al. [22]. The Italian Program to Enhance Relations and Communications Skills (PERCSItaly), established in two hospitals in Milan in 2008, has been shown to improve healthcare 
providers' self-reported professional skills, decrease anxiety, and enhance self-confidence during difficult conversations with patients.

One study in this Special Issue did not directly concentrate on patient engagement but on community engagement and empowerment and public health actions. Against the background of the global COVID-19 pandemic and its accompanying infodemic, Rubinelli et al. [23] aimed to detect targets for fostering critical health literacy in the population. Following argumentation theory, the authors performed a textual analysis of instances of health information and suggested that strengthening individuals' skills in identifying and assessing arguments might be the path forward to empower the public in critically appraising health information.

The cross-sectional study by Gilles et al. [24] also focused on the current pandemic, assessing the professional well-being and their intent to stay by health care workers who were reassigned during the first pandemic wave in Switzerland. The findings indicated that not being able to choose to accept or decline a reassignment to the frontline of the COVID19 crisis might negatively affect healthcare workers' well-being and increase turnover intention. However, the responsiveness of hospital management was found to moderate this relationship. Thus, the authors call for hospitals and healthcare institutions to be responsive to healthcare workers and offer solutions adapted to their needs, such as flexible schedules and extraordinary leaves. Another study revolving around healthcare providers' emotional well-being and mental health is a systematic review by Busch et al. [25], which gives an overview of the existing psychological support resources for second victims in the aftermath of adverse events. The article points out the lack of program availability, in particular outside the United States, and underlines the necessity of establishing programs that provide not only psychological first aid but also medium- and long-term support to enhance individual and, eventually, system resilience. The authors also recommend expanding such programs to healthcare providers suffering from other stressful clinical events, such as workplace violence and pandemic-related traumatic experiences and emotional distress.

Another group deserving special attention and support is the next generation of healthcare providers. Given that patient safety is crucial for delivering high-quality care [26], aspiring healthcare providers should be supported in acquiring adequate patient safety skills [27-29]. To better understand patient safety attitudes among young healthcare workers and healthcare profession students, Tocco-Tussardi et al. [30] synthesized the existing literature and concluded that this population shows overwhelmingly positive attitudes in certain domains, such as teamwork climate and error inevitability but more negative perceptions in other areas, such as safety climate and disclosure responsibility. The authors urge health professions educators and institutions to create a learning culture by integrating patient safety education and training in the curricula of aspiring healthcare professionals and to guarantee that the influential hidden curriculum better reflects the elements of the explicit curriculum. Finally, Fichera and colleagues [31] draw our attention to the still existing gender inequalities in clinical and academic radiology and underline the importance of empowering female radiologists, which may lead to improved professional and emotional well-being and better performance of the entire healthcare system.

Encompassing various articles, the Special Issue "Empowering Patients and Supporting Health Care Providers-New Avenues for High Quality Care and Safety" reflects a wide spectrum of different topics regarding patient care and clinician well-being.

We hope that this collection of original contributions may give rise to exciting new research questions in the field of healthcare quality and safety and accelerate progress towards a resilient and thus high-performing healthcare system that actively engages patients and their caregivers and effectively supports healthcare providers from the very beginning of their career.

Author Contributions: Conceptualization, I.M.B., M.R. Writing—original draft, I.M.B., M.R. Writingreview \& editing, I.M.B., M.R. All authors have read and agreed to the published version of the manuscript. 
Funding: This research received no external funding.

Institutional Review Board Statement: Not applicable.

Informed Consent Statement: Not applicable.

Data Availability Statement: Not applicable.

Conflicts of Interest: The authors declare no conflict of interest.

\section{References}

1. National Patient Safety Foundation's Lucian Leape Institute. Safety is Personal: Partnering with Patients and Families for the Safest Care; National Patient Safety Foundation: Boston, MA, USA, 2014.

2. The National Patient Safety Foundation's Lucian Leape Institute. Shining a Light: Safer Health Care Through Transparency; National Patient Safety Foundation: Boston, MA, USA, 2015.

3. Beach, M.C.; Sugarman, J.; Johnson, R.L.; Arbelaez, J.J.; Duggan, P.S.; Cooper, L.A. Do patients treated with dignity report higher satis-faction, adherence, and receipt of preventive care? Ann. Fam. Med. 2005, 3, 331-338. [CrossRef]

4. Haslam, N. Humanising medical practice: The role of empathy. Med. J. Aust. 2007, 187, 381-382. [CrossRef] [PubMed]

5. Busch, I.M.; Moretti, F.; Travaini, G.; Wu, A.W.; Rimondini, M. Humanization of Care: Key Elements Identified by Patients, Caregivers, and Healthcare Providers. A Systematic Review. Patient 2019, 12, 461-474. [CrossRef]

6. Lovato, E.; Minniti, D.; Giacometti, M.; Sacco, R.; Piolatto, A.; Barberis, B.; Papalia, R.; Bert, F.; Siliquini, R. Humanisation in the emergency department of an Italian hospital: New features and patient satisfaction. Emerg. Med. J. 2013, 30, 487-491. [CrossRef]

7. Busch, I.M.; Moretti, F.; Purgato, M.; Barbui, C.; Wu, A.W.; Rimondini, M. Psychological and Psychosomatic Symptoms of Second Victims of Adverse Events: A Systematic Review and Meta-Analysis. J. Patient Saf. 2020, 16, e61-e74. [CrossRef]

8. Grisales-Naranjo, L.V.; Arias-Valencia, M.M. Humanized care: The case of patients subjected to chemotherapy. Invest. Educ. Enferm. 2013, 31, 364-376.

9. Versiani, C.C.; Barbieri, M.; Gabrielloni, M.C.; Fustinoni, S.M. The meaning of humanized childbirth for pregnant women. J. Res. Fundam. Care Online 2015, 7, 1927-1935. [CrossRef]

10. Tambuyzer, E.; Van Audenhove, C. Is perceived patient involvement in mental health care associated with satisfaction and empowerment? Health Expect. 2015, 18, 516-526. [CrossRef] [PubMed]

11. Ashraf, A.A.; Colakoglu, S.; Nguyen, J.T.; Anastasopulos, A.J.; Ibrahim, A.M.; Yueh, J.H.; Lin, S.J.; Tobias, A.M.; Lee, B.T. Patient involvement in the decision-making process improvement satisfaction and quality of life in postmastectomy breast reconstruction. J. Surg. Res. 2013, 184, 665-670. [CrossRef]

12. Rosenstein, A.H. Addressing physician stress, burnout, and com- passion fatigue: The time has come. Isr. J. Health Policy. Res. 2013, 2, 32. [CrossRef]

13. Shanafelt, T.D.; Balch, C.M.; Bechamps, G.; Russell, T.; Dyrbye, L.; Satele, D.; Collicott, P.; Novotny, P.J.; Sloan, J.; Freischlag, J. Burnout and medical errors among American surgeons. Ann. Surg. 2010, 251, 995-1000. [CrossRef]

14. Addis, S.G.; Nega, A.D.; Miretu, D.G. Psychological impact of COVID-19 pandemic on chronic disease patients in Dessie town government and private hospitals, Northeast Ethiopia. Diabetes Metab. Syndr. 2021, 15, 129-135. [CrossRef] [PubMed]

15. Busch, I.M.; Moretti, F.; Mazzi, M.; Wu, A.W.; Rimondini, M. What We Have Learned from Two Decades of Epidemics and Pandemics: A Systematic Review and Meta-Analysis of the Psychological Burden of Frontline Healthcare Workers. Psychother. Psychosom. 2021, 90, 178-190. [CrossRef] [PubMed]

16. Handberg, C.; Werlauff, U.; Højberg, A.L.; Knudsen, L.F. Impact of the COVID-19 pandemic on biopsychosocial health and quality of life among Danish children and adults with neuromuscular diseases (NMD)-Patient reported outcomes from a national survey. PLoS ONE 2021, 16, e0253715. [CrossRef] [PubMed]

17. Knolle, F.; Ronan, L.; Murray, G.K. The impact of the COVID-19 pandemic on mental health in the general population: A comparison between Germany and the UK. BMC Psychol. 2021, 9, 60. [CrossRef]

18. Schäfer, S.K.; Sopp, M.R.; Schanz, C.G.; Staginnus, M.; Göritz, A.S.; Michael, T. Impact of COVID-19 on Public Mental Health and the Buffering Effect of a Sense of Coherence. Psychother. Psychosom. 2020, 89, 386-392. [CrossRef]

19. Lewandowski, R.A.; Lewandowski, J.B.; Ekman, I.; Swedberg, K.; Törnell, J.; Rogers, H.L. Implementation of Person-Centered Care: A Feasibility Study Using the WE-CARE Roadmap. Int. J. Environ. Res. Public Health 2021, 18, 2205. [CrossRef]

20. Madani Larijani, M.; Dumba, C.; Thiessen, H.; Palen, A.; Carr, T.; Vanstone, J.R.; Fourney, D.R.; Hartness, C.; Parker, R.; Groot, G. Development of a Patient-Oriented Intervention to Support Patient-Provider Conversations about Unnecessary Lower Back Pain Imaging. Int. J. Environ. Res. Public Health 2021, 18, 2786. [CrossRef]

21. Van der Velden, N.C.A.; Van Der Kleij, M.B.A.; Lehmann, V.; Smets, E.M.A.; Stouthard, J.M.L.; Henselmans, I.; Hillen, M.A. Communication about Prognosis during Patient-Initiated Second Opinion Consultations in Advanced Cancer Care: An Observational Qualitative Analysis. Int. J. Environ. Res. Public Health 2021, 18, 5694. [CrossRef]

22. Borghi, L.; Meyer, E.C.; Vegni, E.; Oteri, R.; Almagioni, P.; Lamiani, G. Twelve Years of the Italian Program to Enhance Relational and Communication Skills (PERCS). Int. J. Environ. Res. Public Health 2021, 18, 439. [CrossRef]

23. Rubinelli, S.; Ort, A.; Zanini, C.; Fiordelli, M.; Diviani, N. Strengthening Critical Health Literacy for Health Information Appraisal: An Approach from Argumentation Theory. Int. J. Environ. Res. Public Health 2021, 18, 6764. [CrossRef] 
24. Gilles, I.; Mabire, C.; Perriraz, M.; Peytremann-Bridevaux, I. Workplace Well-Being and Intent to Stay by Health Care Workers Reassigned during the First COVID-19 Wave: Results of a Swiss Survey. Int. J. Environ. Res. Public Health 2021, 18, 8976. [CrossRef]

25. Busch, I.M.; Moretti, F.; Campagna, I.; Benoni, R.; Tardivo, S.; Wu, A.W.; Rimondini, M. Promoting the Psychological Well-Being of Healthcare Providers Facing the Burden of Adverse Events: A Systematic Review of Second Victim Support Resources. Int. J. Environ. Res. Public Health 2021, 18, 5080. [CrossRef] [PubMed]

26. Rodziewicz, T.L.; Houseman, B.; Hipskind, J.E. Medical Error Reduction and Prevention; StatPearls Publishing: Treasure Island, FL, USA, 2020.

27. López-Hernández, L.B.; Díaz, B.G.; González, E.O.Z.; Montes-Hernández, K.I.; Díaz, S.S.T.; Toledo-Lozano, C.G.; BustamanteMontes, L.P.; Vázquez-Cárdenas, N.A. Quality and Safety in Healthcare for Medical Students: Challenges and the Road Ahead. Healthcare 2020, 8, 540. [CrossRef] [PubMed]

28. Alwhaibi, M.; AlRuthia, Y.; Almalag, H.; Alkofide, H.; Balkhi, B.; Almejel, A.; Alshammari, F. Pharmacy students' attitudes toward patient safety in Saudi Arabia: A cross-sectional study. BMC Med. Educ. 2020, 20, 275. [CrossRef]

29. Wu, A.W.; Busch, I.M. Patient safety: A new basic science for professional education. GMS J. Med. Educ. 2019, 36, Doc21. [CrossRef]

30. Tocco Tussardi, I.; Benoni, R.; Moretti, F.; Tardivo, S.; Poli, A.; Wu, A.W.; Rimondini, M.; Busch, I.M. Patient Safety in the Eyes of Aspiring Healthcare Professionals: A Systematic Review of Their Attitudes. Int. J. Environ. Res. Public Health 2021, $18,7524$. [CrossRef]

31. Fichera, G.; Busch, I.M.; Rimondini, M.; Motta, R.; Giraudo, C. Is Empowerment of Female Radiologists Still Needed? Findings of a Systematic Review. Int. J. Environ. Res. Public Health 2021, 18, 1542. [CrossRef] 